\title{
ChemComm
}

Cite this: Chem. Commun., 2013, 49, 9266

Received 19th July 2013, Accepted 13th August 2013

DOI: $10.1039 /$ c3cc45469j

\section{Hypervalent iodine(III)-induced oxidative [4+2] annulation of o-phenylenediamines and electron- deficient alkynes: direct synthesis of quinoxalines from alkyne substrates under metal-free conditions $\uparrow$}

\author{
Sota Okumura, ${ }^{a}$ Youhei Takeda, ${ }^{\text {ab }}$ Kensuke Kiyokawa ${ }^{a}$ and Satoshi Minakata*a
}

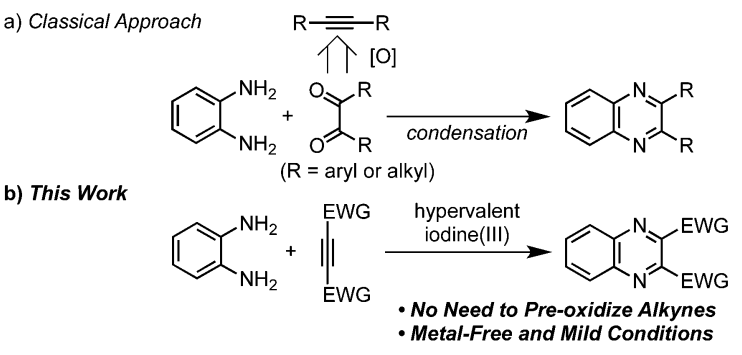

Scheme 1 Synthetic approaches to quinoxalines.
Hypervalent iodine(III)-induced oxidative [4+2] annulation of o-phenylenediamines and electron-deficient alkynes under metal-free conditions has been developed. The reaction allows for direct access to quinoxalines bearing two electron-withdrawing groups in an efficient manner.

Quinoxaline derivatives not only constitute an important class of biologically active agents, ${ }^{1}$ but also find tremendous applications in materials science such as luminescent materials ${ }^{2}$ and low-band-gap polymers. ${ }^{3}$ Of the reported methods, ${ }^{4}$ the most widely used approach involves condensation of $o$-phenylenediamines with 1,2-dicarbonyl compounds bearing electron-rich or neutral substituents, which are generally prepared by oxidation of upstream alkynes (Scheme 1a). On the other hand, the synthetic methods of the quinoxalines bearing electron-withdrawing groups (EWGs, e.g., $-\mathrm{COR},-\mathrm{CO}_{2} \mathrm{R},-\mathrm{SO}_{2} \mathrm{R}$ ) have been poorly explored, ${ }^{5}$ although such compounds can serve as promising candidates for (opto)electronic materials ${ }^{5 a, 6}$ and as versatile synthetic intermediates. Herein we present a hypervalent iodine(III) reagent-induced oxidative [4+2] annulation of $o$-phenylenediamines and electron-deficient alkynes (Scheme 1b), which allows for direct access to electron-deficient quinoxalines from alkynes instead of diketo substrates in an efficient manner.

Recently, we have reported an oxidative dimerization of anilines through the agency of a unique and powerful iodinating reagent, tertbutyl hypoiodite ( $t$-BuOI), leading to aromatic azo compounds in an efficient and selective manner. ${ }^{7}$ The key to the success is an efficient two-fold iodination of nitrogen-center, forming $\mathrm{ArNI}_{2}$ species which then serves as an electrophile to form $\mathrm{N}-\mathrm{N}$ bonds. Based on the findings, we envisioned that a tandem process consisting of (i) the Michael-addition of $o$-phenylenediamine to an electron-deficient alkyne and (ii) a subsequent nucleophilic attack on the highly

\footnotetext{
${ }^{a}$ Department of Applied Chemistry, Graduate School of Engineering, Osaka University, Yamadaoka 2-1, Suita, Osaka 565-0871, Japan. E-mail: minakata@chem.eng.osaka-u.ac.jp; Fax: +81-6-6879-7402; Tel: +81-6-6879-7400

${ }^{b}$ Frontier Research Base for Global Young Researchers, Graduate School of Engineering, Osaka University, Yamadaoka 2-1, Suita, Osaka 565-0871, Japan. E-mail: takeda@chem.eng.osaka-u.ac.jp

$\dagger$ Electronic supplementary information (ESI) available: Procedure for the synthesis and experimental data for quinoxalines and NMR spectra. See DOI: 10.1039/c3cc45469j
}

electrophilic $\mathrm{N}$-center $\left(\mathrm{NI}_{2}\right)$ by the resulting enamine could form a dihydro-quinoxaline skeleton. The subsequent elimination of $\mathrm{HI}$ would produce quinoxalines. At the outset, we attempted the oxidative annulation of $o$-phenylenediamine (1a) and DMAD (2a) as a model reaction (Table 1). However, contrary to our preliminary expectation, the results were disappointing: the treatment of an equimolar mixture of $1 \mathrm{a}$ and 2a with $t$-BuOI ( 4 equiv.) at $-20{ }^{\circ} \mathrm{C}$ gave cis,cis-mucononitrile (5) as a major product, which should be formed through oxidative dearomatization and the following $\mathrm{C}-\mathrm{C}$ bond cleavage of the benzene core (entries 1 and 2). ${ }^{8}$ These results clearly suggested that $t$-BuOI is not an appropriate oxidant for the aimed transformation, probably due to the rapid $\mathrm{H}-\mathrm{I}$ exchange and dearomatization processes of 1a prior to Michael-addition. After extensive screening of iodinecontaining reagents, we were delighted to find that the employment of phenyliodine diacetate (PIDA) was highly effective for the progression of the desired annulation (entries 3-6). It should be noted that protecting group-free phenylenediamines, which are usually labile to oxidation reactions, were applicable to the annulation. Hypervalent iodine(III) compounds have been emerging as powerful reagents in organic synthesis due to their diverse reactivity as well as to highavailability and environmentally-benign character. ${ }^{9}$ Specifically, PIDA and its derivatives have been utilized to develop privileged oxidative $\mathrm{C}-\mathrm{N}$ bond forming reactions. ${ }^{10,11}$ Nonetheless, to the best of our knowledge, hypervalent iodine(III)-mediated oxidative annulation reaction that leads to quinoxaline, has not been reported to date. ${ }^{12}$ Intriguingly, a significant solvent effect was observed (entries 3-6): as the polarity of solvent increased, the yield of 3a was enhanced while that of the by-product $4 \mathbf{a}^{13}$ was decreased. ${ }^{14}$ Other representative 
Table 1 Summary of the screening of the reaction conditions ${ }^{a}$

\begin{tabular}{|c|c|c|c|c|c|c|}
\hline & 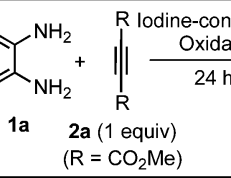 & 3a & & & 5 & \\
\hline \multirow[b]{2}{*}{ Entry } & \multirow[b]{2}{*}{ Oxidant (equiv.) } & \multirow[b]{2}{*}{ Solvent } & \multirow[b]{2}{*}{$T\left[{ }^{\circ} \mathrm{C}\right]$} & \multicolumn{2}{|c|}{ Yield $^{b}[\%]$} & \\
\hline & & & & $3 \mathbf{a}$ & $4 \mathbf{a}$ & 5 \\
\hline 1 & $t$-BuOI (4) & THF & -20 & 12 & 0 & 64 \\
\hline 2 & $t$-BuOI (4) & DME & -20 & 2 & 0 & 33 \\
\hline 3 & $\mathrm{PhI}(\mathrm{OAc})_{2}(2)$ & $\mathrm{CH}_{2} \mathrm{Cl}_{2}$ & -20 & 5 & 40 & 0 \\
\hline 4 & $\mathrm{PhI}(\mathrm{OAc})_{2}(2)$ & THF & -20 & 63 & 18 & 0 \\
\hline 5 & $\mathrm{PhI}(\mathrm{OAc})_{2}(2)$ & DME & -20 & $60^{c}$ & 4 & 0 \\
\hline 6 & $\mathrm{PhI}(\mathrm{OAc})_{2}(2)$ & DMF & -20 & $92^{c}$ & 4 & 0 \\
\hline 7 & $\mathrm{PhI}\left(\mathrm{OCOCF}_{3}\right)_{2}(2)$ & DMF & -20 & 3 & - & 0 \\
\hline 8 & $\mathrm{PhI}=\mathrm{O}(2)$ & DMF & -20 & 0 & - & 0 \\
\hline 9 & & DMF & -20 & 0 & - & 0 \\
\hline 10 & PhI(OH)OTs (2) & DMF & -20 & 0 & - & 0 \\
\hline 11 & - & DMF & -20 & 0 & 21 & 0 \\
\hline
\end{tabular}

${ }^{a}$ Reaction conditions: $1 \mathrm{a}(0.25 \mathrm{mmol}), 2 \mathrm{a}(0.25 \mathrm{mmol})$, and iodinecontaining oxidant $(0.50-1.0 \mathrm{mmol})$ were mixed in a solvent $(3 \mathrm{~mL})$ at the temperature in the column and stirred for $24 \mathrm{~h} .{ }^{b}{ }^{1} \mathrm{H}$ NMR yields. ${ }^{c}$ Isolated yield.

hypervalent iodine(III) reagents were found ineffective for the annulation (entries 7-10), and PIDA was indispensable for the annulation reaction (entry 11).

Having optimized the reaction conditions, the scope of the annulation was investigated (Table 2). A wide variety of diamines bearing an electron-rich, -neutral, and -deficient substituent reacted

Table 2 Scope of the oxidative [4+2] annulation ${ }^{a, b}$

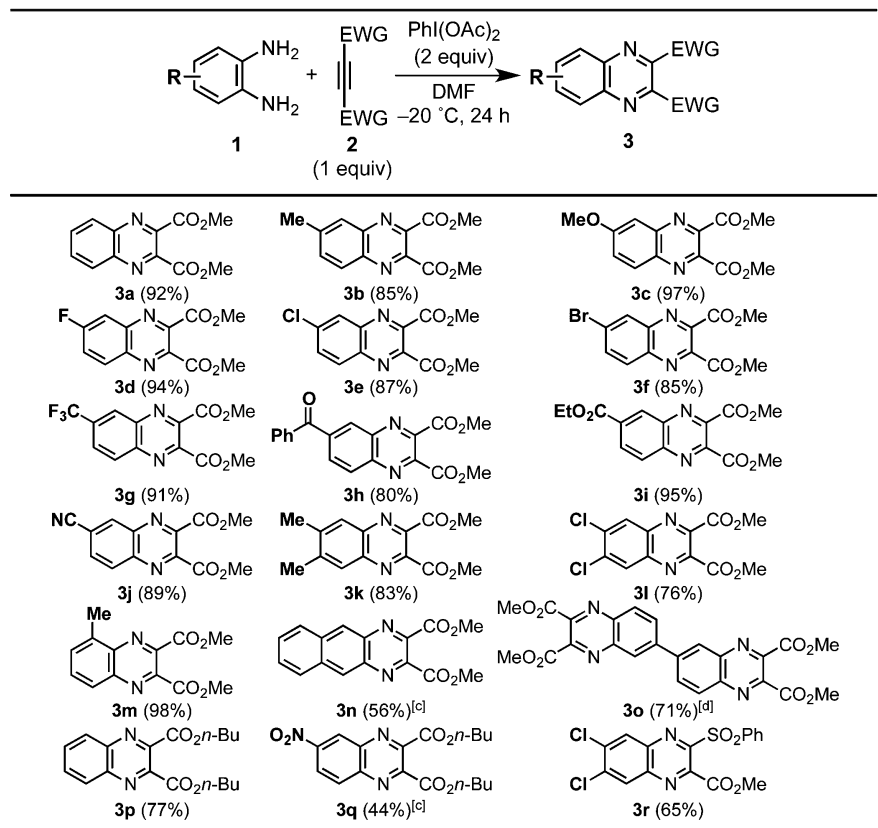

${ }^{a}$ Reaction conditions: 1 (0.25 mmol), $2(0.25 \mathrm{mmol})$, and $\mathrm{PhI}(\mathrm{OAc})_{2}$ $(0.50 \mathrm{mmol})$ were mixed in DMF $(3 \mathrm{~mL})$ at $20{ }^{\circ} \mathrm{C}$ and stirred for $24 \mathrm{~h} .{ }^{b}$ The values in parentheses indicate the yields of quinoxaline products. ${ }^{c}$ Reaction time: $48 \mathrm{~h}$. ${ }^{d}\left[1,1^{\prime}\right.$-biphenyl] $3,33^{\prime}, 4,4^{\prime}$-tetraamine (1o) $(0.25 \mathrm{mmol})$, 2a $(0.50 \mathrm{mmol}), \mathrm{PhI}(\mathrm{OAc})_{2}(1.0 \mathrm{mmol})$ were employed.

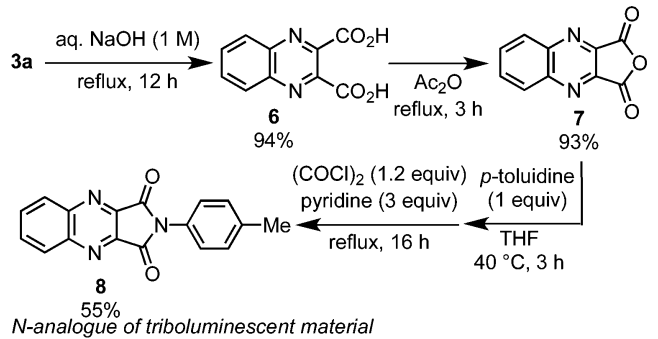

Scheme 2 Derivatization of $3 a$.

with DMAD to give corresponding quinoxalines $\mathbf{3 b} \mathbf{b} \mathbf{3} \mathbf{j}$ in high yields. Multiple-substituted diamines afforded $3 \mathbf{k}$ and $3 \mathbf{l}$. Furthermore, sterically demanding diamines gave the corresponding product $\mathbf{3 m}$ in excellent yield. Although the reaction of naphthalene-2,3-diamine with DMAD required prolonged time, N-heteroacene $3 \mathbf{n}$, which constitutes a family of electron-transporting materials, ${ }^{15}$ was obtained in $56 \%$ yield. Using the method, biquinoxaline 30 was prepared in good yield. In respect to alkyne substrates, dibutyl acetylenedicarboxylate was successfully applied to the reaction conditions to afford 3p and 3q in $77 \%$ and $44 \%$ yield, respectively. In addition, an unsymmetrical alkyne having an ester and a sulfonyl group also successfully underwent the annulation to give $3 \mathbf{r}$ in good yield.

Taking advantage of the ester functionality, 3a was diversely derivatized into functionalized quinoxalines (Scheme 2). For example, diester of 3a easily underwent hydrolysis to give dicarboxylic acid 6 in high yield, which was further efficiently converted to 7 by dehydration. Moreover, anhydride 7 was successfully transformed into imide-fused quinoxaline 8 by condensation with $p$-toluidine, which is an $\mathrm{N}$-analogue of triboluminescent material. ${ }^{16}$ It is noted that such compounds are quite difficult to prepare by traditional condensation methods. ${ }^{17}$

To investigate the reaction pathways, several experiments were conducted as follows: enamine $\mathbf{9}$, which was readily prepared by the Michael-addition of $N$-Boc-protected $o$-phenylenediamine to DMAD, ${ }^{13}$ was treated with PIDA in the presence of trifluoroacetic acid (Scheme 3) ${ }^{18}$ At $-20{ }^{\circ} \mathrm{C}, 9$ underwent oxidative cyclization to give $N$-Boc dihydroquinoxaline $\mathbf{1 0}$ in $45 \%$ yield, ${ }^{19}$ while 9 was quantitatively recovered in the absence of PIDA. In contrast, at room temperature, quinoxaline $3 \mathrm{a}$ was obtained in $54 \%$ yield. In conjunction with the fact that DMAD does not react with PIDA in the absence of $o$-phenylenediamine, the most likely intermediate of the annulation would be the deprotected counterpart of the Michael-adduct $\mathbf{9}$ as preliminary assumed.

On the basis of the experimental results and knowledge accumulated from the literature about hypervalent iodine(III)mediated oxidative $\mathrm{C}-\mathrm{N}$ bond forming reactions using enamine substrates, ${ }^{20-22}$ conceivable reaction pathways are illustrated in Scheme 4. The reaction would start with Michael addition

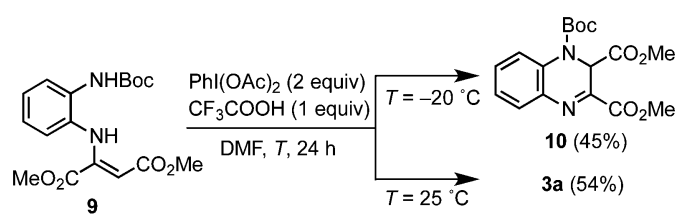

Scheme 3 Oxidative cyclization of enamine $\mathbf{9}$. 


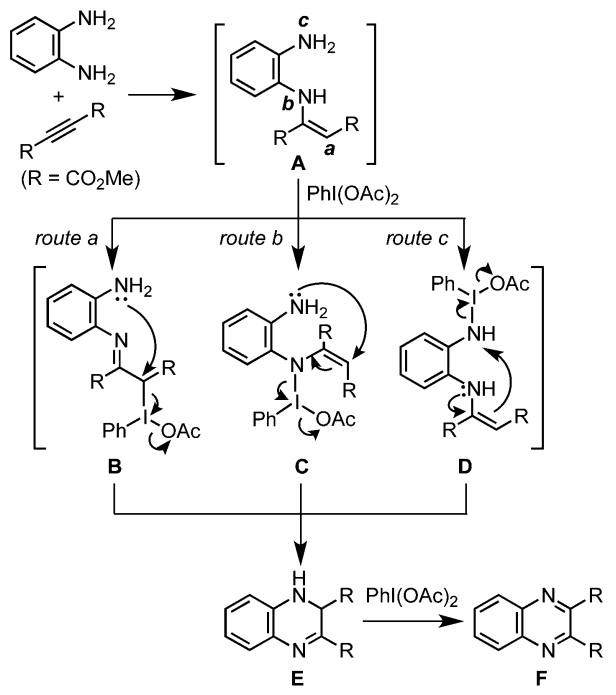

Scheme 4 Conceivable reaction pathways.

of $o$-phenylenediamine to DMAD, forming the enamine intermediate $\mathbf{A}$, which has three possible reactive points when reacting with PIDA, namely, $\beta$-carbon of enamine (a) ${ }^{20}$ enamine nitrogen $(\mathbf{b}),{ }^{21}$ and nitrogen on the benzene moiety $(\mathbf{c}) \cdot{ }^{22}$ Accordingly, three species should be extrapolated as intermediates prior to cyclization: (i) $\alpha$-iodo(III) imine $\mathbf{B}$ (route a); (ii), (iii) enamines $\mathbf{C}$ and $\mathbf{D}$ (routes $\mathbf{b}$ and $\mathbf{c}$, respectively). Successive cyclizative nucleophilic substitution on the iodineattached $\mathrm{sp}^{3}$-carbon (from $\mathbf{B}$ ), on the enamine carbon in a pseudo- $\mathrm{S}_{\mathrm{N}} 2^{\prime}$ manner (from $\mathbf{C}$ ), or on the electrophilic N-center (from D) would provide a common intermediate E. Oxidative aromatization of $\mathbf{E}$ with another equivalent of PIDA should lead to quinoxaline $\mathbf{F}$. Ma and Lei reported an oxidative dimerization of aromatic amines using PIDA to give azobenzenes. ${ }^{22}$ No azo compounds were detected in our system, suggesting that the pathway via intermediacy of $\mathbf{D}$ (route c) might be excluded. On the one hand, according to the reactivity of carbonyl-conjugated enamines (i.e., enaminones) ${ }^{23}$ electrophilic reagents, including iodine electrophiles such as BTMA. $\mathrm{ICl}_{2}{ }^{24 a} \mathrm{I}(\mathrm{Py})_{2} \mathrm{BF}_{4}{ }^{24 b}$ and $\mathrm{CF}_{3} \mathrm{CH}_{2} \mathrm{I}(\mathrm{OH})(\mathrm{OTs}),{ }^{24 c}$ react exclusively at the enamine $\beta$-carbon. Taken together, we believe that the most likely reaction pathway is route a, although routes $\mathrm{b}$, c, and other possible pathways cannot be excluded completely. ${ }^{25}$

In summary, a simple, efficient and metal-free synthesis of electron-deficient quinoxalines through oxidative annulation of $o$-phenylenediamines and alkynes has been developed. Further investigations into the mechanism and application to the construction of functional materials are currently underway in our laboratory.

This research was partly supported by a research Grant from the Ogasawara Foundation for the Promotion of Science \& Engineering (to Y.T.), by a Grant-in-Aid for Scientific Research (B) from the JSPS, Japan (No. 25288047, to S.M.), and by a research grant from the Nagase Science and Technology Foundation (to S.M.). Also, Y.T. acknowledges all support from the Frontier Research Base for Global Young Researchers, Osaka University, from the Program of MEXT.

\section{Notes and references}

1 (a) L. Yan, F.-W. Liu, G.-F. Dai and H.-M. Liu, Bioorg. Med. Chem. Lett., 2007, 17, 609; (b) L. E. Seitz, W. J. Suling and R. C. Reynolds, J. Med. Chem., 2002, 45, 5604.

2 S. Achelle, C. Baudequin and N. Plé, Dyes Pigm., 2013, 98, 575.

3 Y. Zhang, J. Zou, H.-L. Yip, K.-S. Chen, D. F. Zeigler, Y. Sun and A. K.Y. Jen, Chem. Mater., 2011, 23, 2289 and references therein.

4 For reviews of synthetic methods of quinoxalines, see: (a) D. F. Saifina and V. A. Mamedov, Russ. Chem. Rev., 2010, 79, 351; (b) G. Sakata, K. Makino and Y. Kurasawa, Heterocycles, 1988, 27, 2481.

5 (a) P. Gawrys, T. Marszalek, E. Bartnik, M. Kucinska, J. Ulanski and M. Zagorska, Org. Lett., 2011, 13, 6090; (b) T. M. V. D. Pinho e Melo, C. S. J. Lopes, A. M. d'A. Rocha Gonsalves, A. M. Beja, J. A. Paixão, M. R. Silva and L. A. da Veiga, J. Org. Chem., 2001, 67, 66; (c) H. W. Rothkopf, D. Wöhrle, R. Müller and G. Koßmehl, Chem. Ber., 1975, 108, 875.

6 Q. Tang, Z. Liang, J. Liu, J. Xu and Q. Miao, Chem. Commun., 2010, 46, 2977.

7 (a) Y. Takeda, S. Okumura and S. Minakata, Synthesis, 2013, 1029; (b) Y. Takeda, S. Okumura and S. Minakata, Angew. Chem., Int. Ed., 2012, 51, 7804.

8 (a) V. N. Telvelar and H. M. Bachhav, Synlett, 2009, 2059; (b) V. N. Telvekar and B. S. Takale, Tetrahedron Lett., 2010, 51, 3940.

9 (a) T. Dohi and Y. Kita, Chem. Commun., 2009, 2073; (b) V. V. Zhdankin and P. J. Stang, Chem. Rev., 2008, 108, 5299; (c) R. M. Moriarty, J. Org. Chem., 2005, 70, 2893; (d) T. Wirth, Angew. Chem., Int. Ed., 2005, 44, 3656; (e) V. V. Zhdankin and P. J. Stang, Chem. Rev., 2002, 102, 2523.

10 For a review, see: M. A. Ciufolini, N. A. Braun, S. Canesi, M. Ousmer, J. Chang and D. Chai, Synthesis, 2007, 3759.

11 For recent examples, see: (a) J. A. Souto, D. Zian and K. Muñiz, J. Am. Chem. Soc., 2012, 134, 7242; (b) C. Röben, J. A. Souto, Y. González, A. Lishchynskyi and K. Muñiz, Angew. Chem., Int. Ed., 2011, 50, 9478; (c) A. A. Kantak, S. Potavathri, R. A. Barham, K. M. Romano and B. DeBoef, J. Am. Chem. Soc., 2011, 133, 19960; (d) S. Hwan, J. Yoon and S. Chang, J. Am. Chem. Soc., 2011, 133, 5996; (e) A. P. Antonchick, R. Samanta, K. Kulikov and J. Lategahn, Angew. Chem., Int. Ed., 2011, 50, 8605; $(f)$ Y. Du, R. Liu, G. Linn and K. Zhao, Org. Lett., 2006, 8, 5919; $(g)$ M. Ousmer, N. A. Braun, C. Bavoux, M. Perrin and M. A. Ciufolini, J. Am. Chem. Soc., 2001, 123, 7534.

12 Two-step synthesis of quinoxalines through hypervalent iodine(III)mediated oxidation of alkynes and condensation of the resultant diketones with diamines has been reported: M. Tingoli, M. Mazzella, B. Panunzi and A. Tuzi, Eur. J. Org. Chem., 2011, 399.

13 G. Choudhary and R. K. Peddinti, Green Chem., 2011, 13, 3290.

14 For the detailed explanation, see the ESI+.

15 U. H. F. Bunz, J. U. Engelhart, B. D. Lindner and M. Schaffroth, Angew. Chem., Int. Ed., 2013, 52, 3810.

16 H. Nakayama, J. Nishida, N. Takada, H. Sato and Y. Yamashita, Chem. Mater., 2012, 24, 671.

17 L. Hanaineh-Abdelnour, S. Bayyuk and R. Theodorie, Tetrahedron, 1999, 55, 11859.

18 Although we have tried preparation of the Michael-adduct starting from 1a (deprotection form of 9 ) by a similar method reported in ref. 13 , it failed only to produce $\mathbf{4 a}$ alone. Trifluoroacetic acid was added for the purpose of detaching the Boc group of resulting intermediates.

19 The deprotected counterpart of 9 was not formed at all.

20 P. Gao, J. Liu and Y. Wei, Org. Lett., 2013, 15, 2872.

21 (a) W. Liu, C. Chen and Q. Zhang, Org. Biomol. Chem., 2011, 9, 6484; (b) W. Liu, H. Jiang and L. Huang, Org. Lett., 2010, 12, 312; (c) J.-Y. Wang, S.-P. Liu and W. Yu, Synlett, 2009, 2529; (d) X. Li, Y. Du, Z. Liang, X. Li, Y. Pan and K. Zhao, Org. Lett., 2009, 11, 2643; (e) W. Yu, Y. Du and K. Zhao, Org. Lett., 2009, 11, 2417.

22 H. Ma, W. Li, J. Wang, G. Xiao, Y. Gong, C. Qi, Y. Feng, X. Li, Z. Bao, Q. Cao, Q. Sun, C. Veaceslav, F. Wang and Z. Lei, Tetrahedron, 2012, 68, 8358.

23 (a) G. Negri, C. Kascheres and A. J. Kascheres, J. Heterocycl. Chem., 2004, 41, 461; (b) A.-Z. A. Elassar and A. A. El-Khair, Tetrahedron, 2003, 59, 8463; (c) J. V. Greenhill, Chem. Soc. Rev., 1977, 6, 277.

24 (a) C. P. Kordik and A. B. Reitz, J. Org. Chem., 1996, 61, 5644; (b) P. J. Campos, J. Arranz and M. A. Rodriguez, Tetrahedron Lett., 1997, 38, 8397; (c) I. Papoutsis, S. Spyroudis, A. Varvoglis, J. A. Callies and V. V. Zhdankin, Tetrahedron Lett., 1997, 38, 8401.

25 Diels-Alder reaction of oxidatively generated 1,2-diimines and DMAD might be possible, although the matching of the frontier orbitals of these substrates are less likely to be favorable. 